2011-07-06

\title{
Mormon Fertility in Latin America
}

Kiira Elizabeth Fox

Brigham Young University - Provo

Follow this and additional works at: https://scholarsarchive.byu.edu/etd

Part of the Sociology Commons

\section{BYU ScholarsArchive Citation}

Fox, Kiira Elizabeth, "Mormon Fertility in Latin America" (2011). Theses and Dissertations. 3050.

https://scholarsarchive.byu.edu/etd/3050

This Thesis is brought to you for free and open access by BYU ScholarsArchive. It has been accepted for inclusion in Theses and Dissertations by an authorized administrator of BYU ScholarsArchive. For more information, please contact scholarsarchive@byu.edu, ellen_amatangelo@byu.edu. 


\title{
Mormon Fertility in Latin America
}

\section{Kiira Fox}

A thesis submitted to the faculty of

Brigham Young University

in partial fulfillment of the requirements for the degree of

Master of Science

Tim B. Heaton, Chair

Renata T. Forste

Cardell K. Jacobson

\author{
Department of Sociology \\ Brigham Young University
}

August 2011

Copyright (C) 2011 Kiira Fox

All Rights Reserved 


\section{ABSTRACT \\ Mormon Fertility in Latin America \\ Kiira Fox \\ Department of Sociology, BYU \\ Master of Science}

While previous research has identified religion as an influence of fertility, how context changes the nature of that relationship remains little understood. Using census data from Brazil, Chile and Mexico, this study examines whether the high fertility pattern of one pronatalist, American-born religion (The Church of Jesus Christ of Latter-day Saints) translates to the Latin American context. Results indicate that it does, but only inconsistently as the pronatalist pattern is masked by members' educational attainment and mixed religion marriages. When these attributes are accounted for LDS fertility is high in Latin America, especially among the more educated. This study highlights both the importance of member characteristics in influencing fertility and the role of selective recruiting in determining how and whether these characteristics vary by context.

Keywords: fertility, religion, pronatalist, Mormon, Latter-day Saints, Latin America, Chile, Brazil, Mexico 


\section{ACKNOWLEDGEMENTS}

I would like to thank my committee for their support and guidance throughout this project. Tim, thank you especially for your insight, patience and time. Renata, thank you for making all of this possible. From you two I have learned so much. I would also like to thank my family and friends, particularly my amazing parents, for believing in and supporting me. Ka'imi, as always, thank you for keeping me sane. I could not have done this without you. 


\section{TABLE OF CONTENTS}

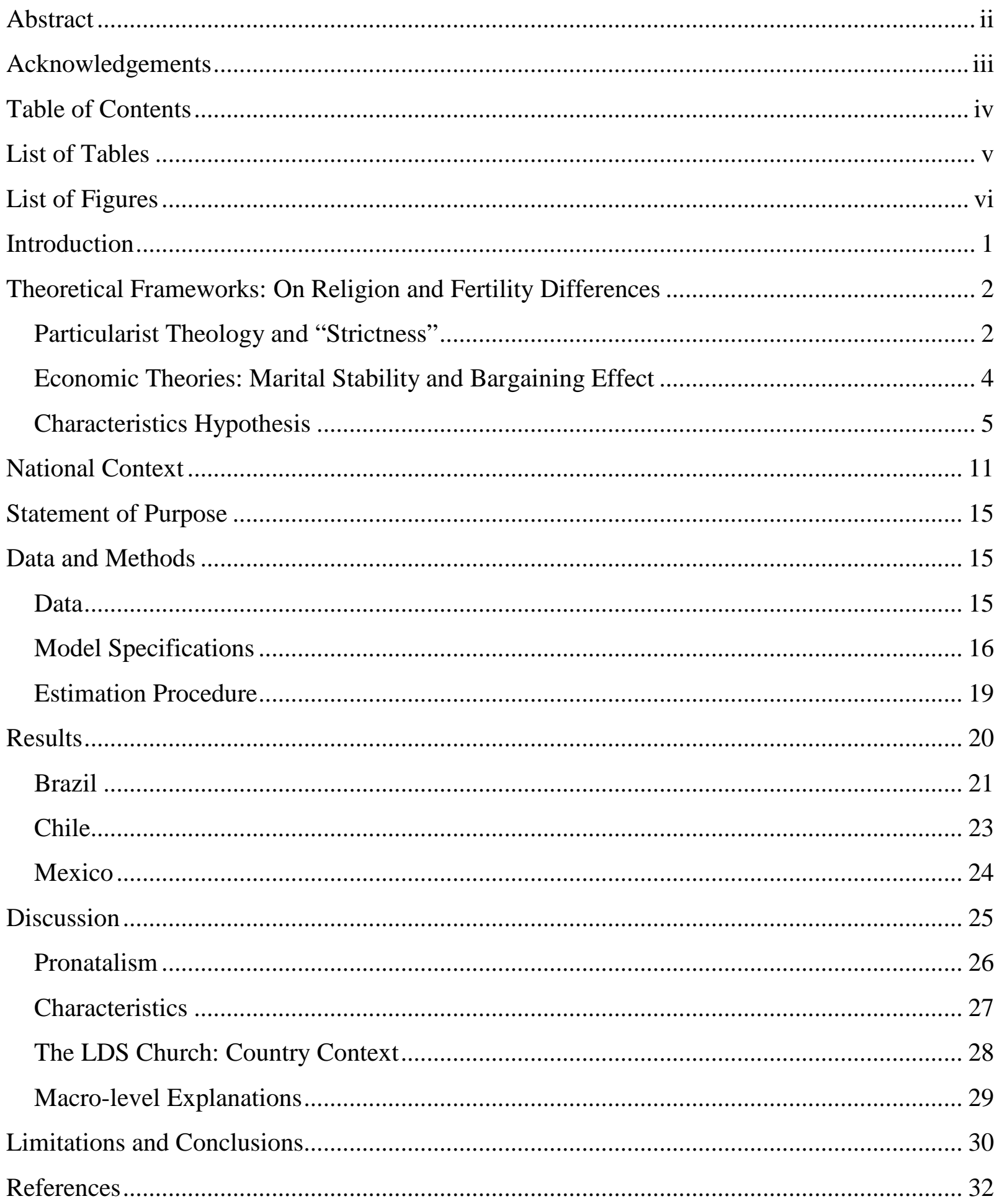




\section{LIST OF TABLES}

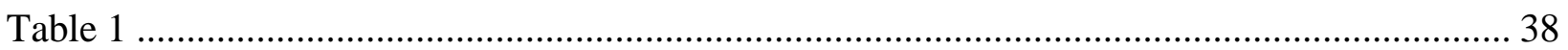

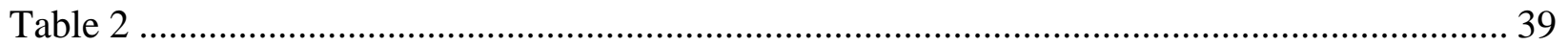

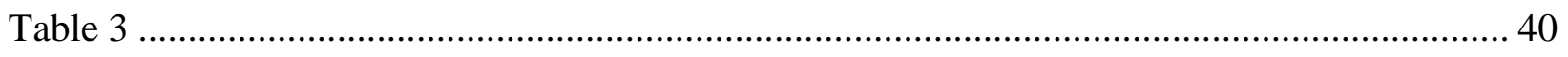

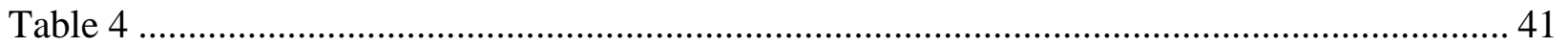

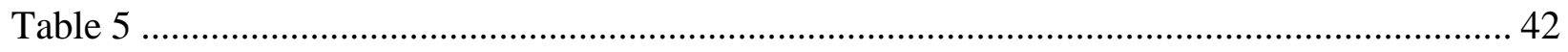




\section{LIST OF FIGURES}

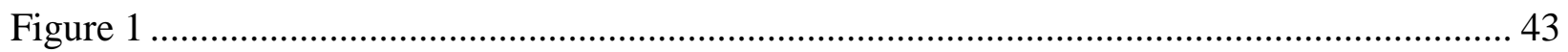

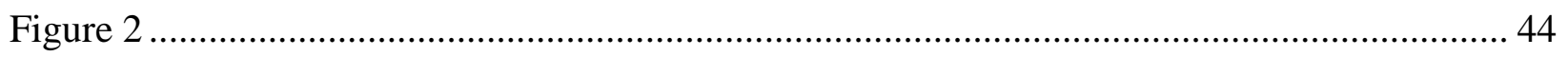

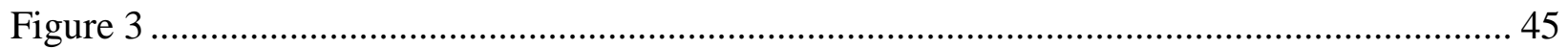

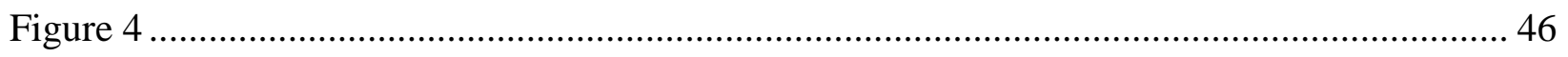




\section{Mormon Fertility in Latin America}

\section{INTRODUCTION}

That pronatalist denominations in the United States have higher fertility than other religions is well-established. The extent to which this relationship translates to other contexts, however, is less understood. In this study I use the case of the Church of Jesus Christ of Latterday Saints (LDS or Mormons) to examine how context affects the relationship between pronatalism and fertility in three other countries. Because this American-born faith has experienced significant international growth over the last few decades (particularly in Latin America) it represents a religion in which different congregations experience very diverse social, economic and political influences. The LDS faith is also a religion with a highly standardized and pronatalist doctrine that it teaches throughout the world. Because the Church's structure and theology remain essentially uniform in vastly diverse settings the faith offers an interesting case in which contextual influences might be examined.

While the LDS Church is renowned for its comparatively high fertility in the United States, little is known about the fertility behaviors of its international members. In fact, there is a dearth of knowledge regarding who non-American Mormons are in general. Without knowing the characteristics of these members it is difficult to predict their fertility, even if they are exposed to the same pronatalist doctrine as their American counterparts. Both individual social characteristics such as education and urban residence as well as couple characteristics are among the many influences of family size. The significance of characteristics in influencing fertility may increase or decrease the importance of contextual differences as the type of people attracted to and retained by a given denomination vary by place.

The purpose of this study is to determine who Latin American members are, what their fertility is and how it compares to other groups. I further aim to increase understanding of the 
various theological, demographic and contextual influences on fertility, and ultimately the implications of religious expansion in developing contexts. To do so I employ two sets of theories (four total): particularized theology, characteristics hypothesis, marital stability and bargaining effect. I also use census data from three Latin American countries: Brazil, Chile, and Mexico. I have chosen these nations not only because their census includes questions on religion, but also because they have the largest LDS populations in the region.

\section{THEORETICAL FRAMEWORKS: ON RELIGION AND FERTILITY DIFFERENCES} PARTICULARIST THEOLOGY AND "STRICTNESS"

Heineck (2005) identified a set of theories frequently employed in previous research to explain the mechanisms through which religion operates to influence fertility: "particularist theology” and "characteristics approach.” The two are not mutually exclusive. "Particularist theology” points to the influence of a denomination's doctrine on family, predicting that affiliation with a pronatalist church will yield higher fertility among members (Goldscheider, 1971, 1999; McQuillan, 2004; Heineck, 2005). It is thus significant that the LDS Church preaches a uniformly staunch pronatalist doctrine throughout the world (Heaton, 1998a:111, Heaton, 1998b:425). In fact, the biblical directive to, “multiply, and replenish the earth" is at the heart of what Mormons believe to be divinely decreed tenets on the family (Genesis 1:28). This theology is made even more meaningful for members as the Church considers the nature of families to be eternal (Heaton 1998b:425). In the case of the Mormons it is difficult, however, to distinguish between the influence of doctrine and culture. While this pro-family doctrine is fairly standardized across borders, whether or not American LDS culture is transferred overseas in the

proselyting process is unclear. Because the pronatalist family ideals embraced by members in the United States may be more a function of culture rather than doctrine, the extent to which Latin American members are exposed to similarly pronatalist values is also unknown. 
According to particularist theory, Mormon fertility behavior will reflect their pronatalist theology. This explanation appears to be insufficient, however, when considering that other denominations have low fertility rates despite a similarly profamily doctrine. What, then, makes the difference? I argue that only “strict” pronatalist churches yield large family size. Kelley (1986) and later Iannaccone (1994) identify such religions as having conservative doctrine that is “closed, comprehensive, and eternal.” They are able to attract and retain members because they demand "complete loyalty, unwavering belief, and rigid adherence to a distinctive lifestyle.” In fact, members of strict churches often adhere to specific diets, ways of dressing or language unique to that religion. "Lenient" churches, on the other hand, exhibit traits such as "relativism, diversity, and dialogue” (Kelley, 1986:79-84; Iannaccone 1994:1182). With respect to fertility specifically, a religion has the greatest influence on the behaviors of its members "when religious authorities have at their disposal a menu of rewards and sanctions that will encourage the faithful to conform” (McQuillan, 2004). According to McQuillan (2004), this is most likely to happen when the faith is "able to build a network of religious institutions that play a formative role in the lives of members and to exercise influence over civil institutions in society as well.” Not only does Iannaccone (1994) classify Mormons as strict, the faith meets these conditions established by Mcquillan as well (see Heaton et al., 2004).

Using these classifications I have developed a typology with which the fertility behavior of Mormons in Latin America might be compared. It is comprised of four basic types: pronatalist and strict, pronatalist and not strict, not pronatalist and strict, and not pronatalist and not strict. Based upon the criteria established in Iannaccone’s (1994) study, Mormons are considered strict, moderate mainline denominations (such as evangelical Lutheran) less strict, and liberal mainline denominations (such as Episcopalians and Methodists) the least strict. Catholics were not 
identified as strict but they are undoubtedly pronatalist (Zhang, 2008). As it is difficult to definitively distinguish pronatalist versus non-pronatalist churches I use this typology to guide my research but do not identify churches representing each type. Instead, I look at two groups I am confident are pronatalist (Mormons and Catholics) but represent strict and not strict, respectively. I then compare these two groups to other Latin American religions that represent either strict or not strict denominations with varying levels of pronatalism. In this analysis Jehovah’s Witnesses and Seventh-day Adventists represent strict religions; mainline (or historic) protestant and evangelical denominations represent non-strict religions.

Demographic information available on American Mormons supports the hypothesis that the combination of strict and pronatalist yields large family size. Research in the United States has shown member fertility is consistently above the national average (Heaton, 1998a:112; Heaton, 1998b:425; Bahr and Forste, 1998:153; Stark, 1994:14; Stark, 1998:60; see Lehrer, 2004; Pitcher et al., 1974; Mosher et al., 1992). Because Church doctrine is fairly standardized across borders, I expect Latin American members will also have higher fertility than the general populations of these countries, despite residing in historically Catholic countries.

\section{ECONOMIC THEORIES: MARITAL STABILITY AND BARGAINING EFFECT}

An aspect of the Church in Latin America, however, that I expect to influence and likely decrease Mormon family size is its relative newness. While the LDS faith has grown substantially in this region throughout the last few decades, its immaturity is reflected in the large percentage of first generation converts (Stark, 1994:14). Not only have new members had less exposure to LDS doctrine and culture, they are more likely to have been raised in a different faith or have a spouse not affiliated with the Church. A high rate of interfaith unions in these areas might result from existing marriages in which one spouse converts to the LDS religion, a 
smaller pool of eligible members from which one might choose a spouse, or fewer social sanctions against interfaith marriages than exist in areas where the LDS Church is more established. Given the prevalence of mixed marriages in Latin America, it is important to understand how fertility is determined in interfaith unions. To do so I employ a set of economically grounded theories also identified by Heineck (2005): “marital stability” and "bargaining effect.” The former suggests that such couples are less likely to make mutual investments in human capital, such as having children, because of the relative instability of their union (Heineck, 2005; Lehrer, 1996). “Bargaining effect,” refers to how fertility behavior is negotiated between couples (Lehrer, 2004). This line of reasoning suggests a Catholic woman married to a Mormon will have more children with him than she would with someone from a less pronatalist faith (Lehrer, 2004). In other words, these theories suggest the high rate of interfaith unions among Latin American members will result in lower levels of fertility.

\section{CHARACTERISTICS HYPOTHESIS}

The second hypothesis identified by Heineck (2005) is the "characteristics hypothesis" which asserts that the relationship between religion and fertility operates through socioeconomic factors. This approach is often used in conjunction with particularist theology, as differences in fertility rates between denominations not accounted for by pronatalism are often attributed to differing individual characteristics (and vice versa). In the case of the Mormons, using both of these theories yields competing hypotheses. Trends in conversion and retention may create a Mormon membership with demographic characteristics that differ from the general population in age structure, educational attainment, urban residence, and mixed member families. This hypothesis is somewhat supported by data from the United States that shows that the LDS population exhibits high rates of church attendance (Heaton et al., 2004:49), is economically 
successful (Heaton et al., 2004; Heaton, 1994:254), is more likely to be married (see Heaton et al., 2004; Heaton, 1994:254; Heaton 1998a:124) and is well-educated (Heaton et al., 2004; Heaton, 1994:254, Heaton 1998a:127). That the general Mormon population is fairly educated is unsurprising. The Church has a strong emphasis on sacred and secular learning ("Education," 2010). In contrast to national trends, however, "active” members tend to have higher educational attainment (Heaton et al., 2004:31). In this way the LDS Church is something of an anomaly in that it appears to attract and retain educated individuals (see Table 2) while concurrently maintaining a high fertility rate.

While knowledge of the LDS population outside of the States is limited, available information reveals two points of interest. First, in keeping with American trends, Mexican Mormons are identified as being more socioeconomically successful and urban than their nonmember counterparts (Heaton et al., 2010; Knowlton, 2005). More specifically, Mexican members are more urbanized than Catholics (Heaton et al., 2010). Lawson (n.d.) also found Latter-day Saints to be more urban, educated, and of higher socioeconomic status than members of other recently transplanted American-born religions. Such demographic characteristics are generally associated with smaller family size. Second, while Heaton (1998b:437) found that a strong negative relationship exists between education and fertility within the Mexican LDS population, the association appeared to be less negative among Mormons in Mexico than in the United States. I will now discuss several other studies that further emphasize the importance of education, as well as urban residence, as influences of fertility.

\section{Education}

While the negative association between female education and fertility has long been recognized, the strength of the relationship varies. Education can be conceptualized as a "sorting 
machine” that actively stratifies individuals throughout the social system (see Kravdal and Rindfuss, 2008). It does so by informing, even determining, various facets of life including one's location, class, attitudes, behaviors and social network. Kravdal (2001) has identified several ways in which a woman's education influences her attitudes and desires relating to fertility. Among the reasons he cites are 1) the high opportunity costs of childbearing, 2) expenses associated with having kids, 3) the diminished importance of children as social insurance in post industrial societies 4) the increased parental (as opposed to community) responsibility for children, and 5) cultures of consumerism. He also points to demographic reasons such as 6) lower mortality rates, 7) delayed marriage and 8) the divorce of sex from marriage, made possible by increased use of contraceptives (Kravdal 2001).

Kravdal and Rindfuss (2008) later expand upon and more succinctly categorize the nondemographic reasons into essentially four mechanisms through which education influences fertility: balancing roles, affording children, using knowledge gained in school, and finding a partner. First, balancing roles encompasses the high opportunity costs of childbearing. As women throughout the world remain primarily responsible for childcare and domestic tasks, they must determine how to balance responsibilities at home with more education and the career opportunities it engenders (Kravdal and Rindfuss, 2008). Given men's traditional role as bread winners, their attempts to balance roles typically places greater focus on financially supporting a family. Because children in non-agricultural societies are economic liabilities, economic theory suggests that those with high incomes will have more children, the second factor mentioned by Kravdal and Rindfuss. Because the opposite is typically true, however, it appears this effect is mitigated by material and other economic desires (see Kravdal and Rindfuss, 2008). The third factor, knowledge, refers to greater awareness and use of contraceptives among the educated. 
Women's education might have the greatest influence in this arena as female methods of birth control are most commonly used (see Kravdal and Rindfuss, 2008) The better educated might also more carefully plan their fertility and childbearing. Finally, finding a partner refers to how educated females with their increased earning capacity are now more frequently viewed positively by potential partners. This in turn allows women to have greater bargaining power in the division of domestic and fertility decisions (Kravdal and Rindfuss, 2008).

Another important consideration is the significance of aggregate-level or 'mass education' on fertility (see Kravdal, 2000). The predominant belief is that the 'spill-over' effect of a highly educated society would alter the behavior of an uneducated individual living within that community (Kravdal, 2000). In a society where general education levels discourage fertility, for instance, increased female education will likely result in a more dramatic decline than would be projected when only considering individual-level data (Kravdal, 2000). Two different studies of African nations support this hypothesis that (higher) community education levels discourage fertility, in part operating through increased prevalence and use of contraceptives (Thomas, 1999; Kravdal, 2000). Kravdal’s (2000) research also suggests that women in areas with relatively high educational attainment have "weaker fertility desires” than they might in areas with lower average education. Note, however, that increases in education do not have uniform influence on fertility throughout the world. Caldwell (1980) suggests that societies with really low aggregate education levels are where the "impact of introducing compulsory education" has the greatest effect on fertility rates (Kravdal, 2000). Because most countries have moved beyond that stage, changes in education are now expected to have a less dramatic influence on fertility (Kravdal, 2000). Regardless of a nation's stage of development, however, the relationship 
between mass education, individual education and fertility has important implications for a faith expanding internationally.

These studies also highlight other contextual factors that affect the relationship between education and fertility. In addition to areas where compulsory education is new, it appears that education has a greater effect on fertility in more gender egalitarian places (Kravdal, 2001). As suggested by Kravdal (2001), the relationship might also have a much less negative effect than believed because sources of "spuriousness" have not previously been taken into account. As suggested by Caldwell (1980), the effect may have decreased over time as well, as indicated in a comparative study of cohorts from 1940 through 1964 (Kravdal and Rindfuss, 2008). They found that the strength of the inverse relationship between fertility and educational attainment was less pronounced over time due to a decrease in fertility among the less educated and an increase in childbirth among those with master degrees (Kravdal and Rindfuss, 2008).

As mentioned above, the relationship between education and fertility is less negative for Mormons in the United States than it is for the general population (Heaton, 1998b:437). This is in part because the fertility-depressing effect of education is offset by exposure and adherence to pronatalist doctrine. High fertility is also encouraged and reinforced by American LDS culture and its distinct beliefs about the family. Because American Mormons tend to interpret pronatalism as being synonymous with high fertility, large families are condoned and to some extent expected. I thus anticipate this relationship will be manifest but less pronounced within other LDS populations with less exposure to American Mormon culture.

Place of Residence: Urban vs. Rural Areas

Another important factor influencing fertility is place of residence. In his study of Zimbabwe Kravdal (2000) found a significant negative relationship between education and 
fertility only when place of residence was not controlled for. Studies in the 1980's supported the belief that different regions have different fertility trends, with urban areas consistently exhibiting lower fertility (Kulu and Boyle, 2009). Not only has this trend held true both before and after the demographic transition, it has appeared throughout the world in places such as France, Italy, Estonia, West Germany, the Netherlands, Austria and Poland, Denmark, Finland, Norway and Sweden and the United States (see Kulu and Boyle, 2009 for a full list of references). As Kulu and Boyle (2009) point out, it also holds across medium, low or lowest fertility countries. Because these effects remained even after controlling for relevant individuallevel socioeconomic characteristics and "housing conditions," the "residential context" appears to have an effect of its own (Kulu and Boyle, 2009). In other words, migrants moving between rural and urban areas might be expected to adapt to the norm in the destination community (Kulu and Boyle, 2009). In addition to this "adaptation effect," "migrant selection effect” might predict that people who want larger families move out of urban areas (Courgeau 1989; Kulu and Boyle, 2009).

As the concept of "adaptation effect" suggests, community-level values exert an important influence on ideals about courtship, marriage and fertility (Szreter 1996; Kulu and Boyle, 2009). In this way the environmental context, comprised of "distinct social, cultural and community groups,” shapes reproductive norms and ideas (Szreter and Garrett 2000; Kulu and Boyle, 2009). A study of sub-Saharan Africa highlights the differences in social and economic context between rural and urban places that affect fertility. These differences are essentially those cited in relation to education: 1) Urban areas adopted contraception more rapidly than other areas, 2) children are not economic assets and they cost more to raise in urban than in rural areas, 3) family networks and ties generally play a less significant role in urban areas, and 4) urban 
women tend to have more education and economic opportunity (see Hollos and Larsen, 2008).

These studies underscore the interrelated nature of education and place of residence as well as the significant influence these characteristics have on fertility. Thus in addition to education, urban residence is another important consideration when examining the fertility of Mormons as proselytizing efforts tend to be concentrated within, and disproportionately recruit members from metro areas (see Table 2).

\section{NATIONAL CONTEXT}

While the aforementioned theories focus on micro-level explanations for Mormon fertility, the national context of fertility is another feature of the Church in Latin America that likely influences member family size. There are three reasons why I expect religion to differentially affect fertility behavior by place, each relating to contradictory national-level trends found in Brazil, Chile and Mexico. Latin America provides an interesting context for examining the demographic behavior of an emerging pronatalist faith because the continent is currently experiencing a decline in both fertility and Catholicism. In fact, fertility decline has been the subject of much research since the demographic transition became manifest in the western world over fifty years ago. After the post-World War II baby-boom, fertility levels dropped in many developed countries, a trend that has not only continued within those nations in subsequent decades but is now seen in many others throughout the world (“The Future," n.d.). Three such countries are Mexico, Brazil, and Chile, all of which now average much smaller family size than they did in the 1960's. At that time each of these countries boasted a total fertility rate of over five or six children per women, but by 2008 averaged from just less than two to a little over three children per woman (“Fertility Rate,” 2010).

To increase understanding of the social contexts and developmental stages of these three Latin American countries, I will now briefly touch on relevant demographic statistics from each. 
To begin with, Chile boasts a population of almost 17 million, eighty-nine percent of which are urban. School life expectancy is fifteen years and the nation's total fertility rate (TFR) is 1.88 children per woman. Seventy percent of the nation's population self-identifies as Roman Catholic, about 15\% claim Evangelical, and 1.1\% Jehovah’s Witness (“World Factbook,” 2011). The LDS Church was introduced in Chile in 1956 and now reports a membership of over 554,733 members (a substantially larger figure than when self-reported) (Church Almanac, 2011). In contrast, Brazil has a population of over $200,000,000,87 \%$ of which are urban. School life expectancy is also 15 years and the country's TFR is a bit higher than Chile's at 2.18 children per woman. Including nominal Catholics, $73.6 \%$ identify as Catholic, $15.4 \%$ as Protestant, and 1.3\% as Spiritualist (“World Factbook,” 2011). Mormonism was introduced in Brazil in about 1927 and the Church there now claims 1,060,292 adherents (Church Almanac, 2011). Finally, Mexico has a population of a little over 113 million, 78\% of which reside in urban areas. Average educational attainment for both sexes is 14 years and the TFR is the highest of these three countries at 2.29 children per woman ("World Factbook," 2011). LDS missionaries entered Mexico towards the end of the $19^{\text {th }}$ century and although the Church experienced slow growth for the first several decades, it now claims 1,197,573 Mexican followers (Church Almanac, 2011). It is important to note, however, that in all three countries Church records report much higher membership than do sources, such as the census, in which religion is selfreported.

These three Latin American countries also share a history of strong Catholic influence in the political and social realms. While there remains significant Catholic presence in these nations where the majority of the population continues to self-identify as members, the influence of the Catholic Church in the public and private spheres has arguably declined (Adsera, 2006a). Loss of 
authority is only one effect of deCatholicism, however. The second is a general drop in adherents (Chaves, 1994) including decreased rates of Catholic affiliation, attendance, and a rise in the population considered "nominal” Catholics (Adsera, 2006a; Adsera, 2006b). The decline in religiosity is perhaps most clearly evidenced by an increase of behaviors incongruent with Catholic teachings such as divorce and abortion ("Country Studies,” 2010). That said, it is important to remember that Catholicism remains a significant part of these nation's national culture.

Between 1980 and 1996, Brazil's Catholic population dropped from 89\% to 76\% (“Country Studies,” 2010). These numbers do not fully reflect the decline, however, as a significant portion of self-identified Catholics are considered to be "baptismal certificate Catholics.” These members typically participate in major religious holidays and rites of passage, but neither attend church regularly nor adhere to its teachings; in fact, as few as 10 to $20 \%$ regularly take part in church activities (“Country Studies,” 2010). Similarly, Chile, a nation wherein 90\% of the population claimed to be Catholic in 1970, experienced a decline of over 13\% by 1992 (“Country Studies,” 2010). Mexico’s rates fell from 96.2 to 89.7\% in approximately the same period of time (“Country Studies,” 2010).

While there appears to be a correlation between falling fertility rates and the decline of a stanchly pronatalist religious monopoly, the relationship is not necessarily causal. Many other macro-level factors have been found to influence fertility, including modernization and economic growth. In fact, when using the Human Development Index or per capita GDP alone, there appears to be an inverse relationship between level of development and total fertility rate, not only in Latin America but throughout the world (“HDI,” 2010; “GDP per Capita,” 2010). Given that the United States, Brazil, Chile and Mexico have differing levels of national development 
this negative association between economic growth and fertility suggest that the fertility of members may vary by country. Thus while the Church's pronatalist doctrine is fairly uniform across borders, macro-level forces may influence how the message is received and the extent to which it influences fertility behaviors.

One might ask why the fertility behaviors of an emerging conservative faith in deCatholicizing nations matters. First of all, the information is meaningful for the LDS Church. Understanding discrepancies in Mormon fertility rates has become increasingly important when considering the recent growth trends of the LDS Church, which now claims a larger global membership than domestic one (Stark, 1998:31). Termed the "Latin Americanization" of the Church (Grover, 2005), membership growth from this region has been particularly high in the last few decades, boasting a 421\% increase between 1980 and 1990 (Stark, 1994:18). The extent to which members in regions with rapidly expanding membership embrace the pronatalist values of the Church will have serious implications for future growth of the LDS faith.

More generally, however, it is important to recognize that the decrease in Catholic influence has yielded a rise in religious diversity within each of these nations (see Heaton et al., 2010). In particular, these countries are witnessing an increase in traditional Protestant, and Protestant evangelical denominations (see Heaton et al., 2010). Not only is the LDS faith one of these groups, it is a unique religion whose members in the United States are typically educated and having large families. Its existence in Latin America begs the question: What happens to the fertility behaviors of a pronatalist faith with educated followers when introduced in nations with contradictory macro-level forces? I expect this research to not only have important implications 
for the LDS community, but to lend insight into an international trend that might significantly shape the religious and cultural make-up of Latin America.

\section{STATEMENT OF PURPOSE}

My purpose is to not only identify how the fertility levels of Mormons differ from the national averages of Mexico, Chile and Brazil, but to explain the difference. To do so I use the competing "characteristics" and "particularized theology" theories to identify how affiliation with a pronatalist religion interacts with the demographic characteristics of members to influence family size. Due to the high rate of interfaith unions and the ability to match spouse responses, I also employ two other theoretical perspectives, “marital stability” or "bargaining effect.” For comparable Mormon/non-Mormon data I examine census data from each of these three historically Catholic countries. Because their national religious atmosphere presents a unique context for the emergence of Mormonism, I consider the influence of macro-level factors in interpreting my results, but my analysis includes only individual-level responses. Informed by previous research and my theoretical frameworks I hypothesize: (1) Mormons will have higher fertility rates than non-Mormons in part because of their pronatalist theology, (2) Mormon fertility will be different from the national average if they have different social characteristics, (3) Mormons will have higher fertility than religions that are lenient and/or not profamily, (4) The prevalence of interfaith unions will result in lower member fertility than that exhibited by American Mormons, and (5) Similar to those in the States, Latin American Mormons will exhibit a less negative relationship between education and fertility than the general population.

\section{DATA AND METHODS}

DATA

This analysis uses the most recent available census data from each of these three countries. Mexico’s most recent was collected in 2000, Chile in 2002, and Brazil in 2000. The 
data were retrieved from Integrated Public Use Microdata Sample (IPUMS) International. According to the IPUMS-International website, sample densities fall between 1 and 10 percent of national populations. Information concerning how this data is collected and might be accessed can be found at https://international.ipums.org/international. Because I am interested in marital fertility and matched partner information when retrieving the data, this sample is limited to either married couples or those in consensual unions. Census data from these countries is useful because it provides information on subpopulations as well as insight into national trends, and the questionnaire contains questions on religious affiliation. The census is also the only source of comparable information for Mormons with a sufficient sample for statistical analysis. That said, census data also has limitations. Importantly, it does not contain questions concerning values, attitudes, beliefs, religiosity, or duration of affiliation with a denomination. I am thus unable to test other potential explanatory factors identified in the literature such as social networks, religiosity or childhood religion in this analysis.

\section{MODEL SPECIFICATIONS}

My dependent variable is the number of children ever born to each woman and my primary independent variable is religious affiliation. Because I believe that Mormon fertility rates can be in part explained by the type of person attracted to the LDS faith, I also include several socioeconomic and demographic variables including educational attainment, rural place of residence, employment status, ethnicity, nativity, and current age of respondent. Because different countries vary in their classification schemes, IPUMS recodes many of their variables, creating “integrated” variables that utilize composite coding schemes to make cross-national census data comparable ("FAQ," n.d.). In other words, the first digit or two of the new code “provides information across all samples;” each subsequent digit is associated with more detail 
and fewer samples. In this analysis marital status, employment status, race, and religion have been recoded using composite coding schemes. No such recoding was necessary for children ever born, age, place of residence or nativity status.

I first created two different LDS religious affiliation variables. The first, used in models 1,2 , and 3, is a measure of the wife's affiliation with the LDS Church (irrespective of her husband's religion). The second, used in models 4 and 5 , is coded into four mutually-exclusive dichotomous variables: (1) Just the wife is LDS, (2) just the husband reports being Mormon, (3) both are affiliated with the LDS Church, and (4) neither spouse self-identifies as LDS. I use these variables to compare different types of LDS couple households and to determine whether interfaith unions exhibit trends different from ones in which both spouses are Mormon. For each of the other denominations included in the study I created variables for wife's affiliation in the same manner as the first type of LDS affiliation variable (irrespective of husband religion). All three countries have measures for wife membership in the Catholic Church, Jehovah's Witness, and some type of Protestant faith. Brazil and Mexico provided more religious categories than did Chile, including denominations such as Seventh-day Adventist and various local Protestant religions.

Based on the categorization of Protestant religions by the Pew Forum on Religion \& Public Life, Protestants in this study were placed into one of three categories. The first is mainline Protestant which consists of Methodists, Presbyterians, Lutherans, Baptists, Anglicans, Congregationalists, and Episcopalians, if their identification is available in the data. The second category is "other" types of Protestant religions that are neither considered mainline nor are specific to that country. Included in this category are members of the Pentecostal, Assembly of God, Church of the Nazarene, Apostolic, generic Christian, and Evangelical Churches, (if this 
identification is given in the data). The third Protestant category is what I have termed "local Protestants," referring to Protestant denominations that are unique to that area. ${ }^{1}$ This category is congruent with the codes for religions in both nations' census

Educational attainment is an ordinal variable consisting of four categories that have been recoded by IPUMS International: (1) Less than complete primary, (2) complete primary, (3) incomplete secondary, and (4) complete secondary or above. Urban/rural residence is a dichotomous variable. Employment status is coded into three dichotomous variables: (1) Employed, (2) unemployed and (3) inactive in the workforce, with "employed" used as the reference category. Only Brazil provided racial categories from which I coded five dummy variables: White, Black, Indigenous, Asian and Brown (Brazilian), with "White” used as the implicit category. Nativity status (whether or not the individual is foreign born) is a dichotomous variable coded native/not native. I coded these characteristics for females as well as their husbands.

I used a combination of multiple imputation and mean substitution to handle data missing from the couple's socioeconomic characteristic variables. Because Brazil’s census was missing very little data I used mean substitution only for its race measure. Any additional missing cases were dropped from analysis. In Mexico and Chile most of the missing data were from the spouse demographic characteristics which I include in this analysis primarily as controls. In an effort to retain these cases I used mean substitution and then multiple imputation for Mexico's maternal education measure, one of the most significant variables in this study.

\footnotetext{
${ }^{1}$ In Mexico local Protestants include Cuaquera, Disciples of Christ, Christian Friendship Church, Prayer House Church, Faith Center, Agape Force Church, Alpha and Omega Church, Living Water Church, Church of God, Church of God of Prophecy, Complete Gospel Church, Angular Stone Voice Church, Pentecostal Missionary, Christian Societies, Evangelical societies, Pentecostal societies, Independent Pentecostal, variations of Evangelical Christian and Pentecostal denominations, Traditionalists, Living God Light of the World, and Christ Church.

In Brazil it includes Brazilian Catholic Apostolic, Brazil for Christ, Foursquare Gospel, Universal of the Kingdom of God, House of the Blessing, House of Prayer, God is Love, Maranata, other types of Catholic, Chain of Prayer Pentecostal, Religion of God, and various versions of local Evangelical Pentecostal and Protestant groups.
} 
Cases missing from these nations' dependent variables were dropped from analysis. Sample size and percent missing for Brazil, Chile and Mexico are now 2,003,124 and 0.5\%, 299,256 and $3.0 \%$, and $1,998,830$ and $2.0 \%$ respectively.

\section{ESTIMATION PROCEDURE}

Analyses were run in STATA using negative binomial regression to account for the nonnormal distribution of number of children born. Corresponding with my hypotheses I ran five models for each country; fifteen models in total. The first model contained only the wife's religion as an explanatory variable with a control for age of respondent. With this model I am able to determine how the fertility of each nation's Mormon group compares to their general population. To test my second hypothesis, the "characteristics approach," and determine the role that member characteristics play in Mormon fertility, the second model included the social characteristics of both wives and husbands. In addition to wife's religion and age, I added educational attainment, employment (with employed as the explicit category), race dummy variables, rural place of residence, and nativity status measures for both spouses.

The third model compared the fertility of Mormons to the aforementioned religious groups to determine whether a strict, pronatalist religion yields higher fertility than groups with only one or neither of those qualities. In addition to the variables included in the second model, to the third I added measures for wives' affiliation with the Catholics, Jehovah's Witnesses, Seventh-day Adventists, mainline Protestants, other Protestants and local Protestants, if available. This model tests my third hypothesis which predicts that Mormons will have higher fertility than faiths not considered both strict and profamily.

To test my fourth hypothesis, I included the spouse characteristics and added three LDS religious affiliation variables: (1) Just the wife is LDS, (2) Just the husband is LDS and, (3) both 
husband and wife are Mormon. Households in which neither spouse is LDS are the reference category. For the purpose of comparison, the number and percentage of each household type by country are listed in Table 1. In this model I used mutually exclusive spouse religion categories to determine whether interfaith unions affect fertility differently than religiously homogenous ones.

[Table 1 about here]

Finally, for my fifth model I created three different interaction terms using the LDS religious affiliation variables (included in the above model) and female education. These measures indicate the effect of women's education on fertility by household type. More specifically, from these variables I am able to better understand how education influences the fertility of LDS women, LDS men, and homogenously Mormon couples. Socioeconomic characteristics for both spouses were also included in the model.

\section{RESULTS}

As indicated in the descriptive statistics table (Table 2), trends in LDS women's childbearing are not constant across these three countries. While their fertility is higher than the national average of Chile, it is below that of the general population in Brazil and Mexico. There appear to be trends, however, in the demographic characteristics of LDS women across country. Mormon wives are a little younger (by 2 years or less), more urban, more educated, equally or slightly more likely to be employed, and almost all are native born. Whites represent the majority of both the LDS and general population of Brazil. While differences in educational attainment between groups are more pronounced in Brazil and Mexico than Chile (at about 0.5 vs. 0.1), in all three countries Mormon wives average above a primary education. These trends in the characteristics of LDS wives generally reflect patterns found within the American Mormon population. I will now briefly discuss the important findings from each nation. 
[Table 2 about here]

BRAZIL

The results of negative binomial regression for each country are displayed in tables 3, 4 and 5 respectively. Table 3 provides the results for Brazil. Controlling for age, model one indicates that if the woman is LDS she is likely to have slightly fewer children than the national average. These initial results do not appear to support my first hypothesis that Mormon fertility would be higher in part because of the faith's pronatalist doctrine. When accounting for the socioeconomic characteristics of her and her spouse, however, an LDS woman averages slightly more children than the general population. As shown in model 2, most of the characteristics included are significant and education is negatively associated with fertility for both the respondent and the spouse. Thus the lower fertility exhibited by LDS wives' in the first model is in part explained by Mormon women's higher educational attainment. Figure 1 illustrates the almost 18\% increase in the coefficient between the first and second model, representing the percent of member fertility explained by characteristics. Clearly, characteristics of members do matter.

[Table 3 about here]

The same patterns are exhibited in model three wherein LDS women's fertility is compared to that of other denominations in the country, with Catholics used as the reference group. Only Jehovah’s Witnesses and mainline Protestants have significantly lower fertility than Catholics; Seventh-day Adventists and local Protestants have slightly more children and Mormons have the highest fertility of any group included except for "other Protestants." While the high birth rate of wives belonging to this last category raises interesting questions, the fertility of this group is included for purposes of comparison and thus does not warrant further 
discussion in this study. Generally, these results appear to support my strict/pronatalist typology (hypothesis \#3) with the exception of women belonging to other Protestant religions. It is also important to note that while the explanatory power of the model increased when characteristics were added, the pseudo $\mathrm{R}^{2}$ does not change in the third and subsequent models. This is to be expected; explained variance will not increase in these models because the sample is small.

The fourth model yields similar results except in the significance of wife's LDS affiliation in influencing fertility. In comparing the three types of LDS couples (wife is member, husband is member or both are members) the only type that appears to be significant is when both are Mormon. In this case fertility is slightly higher. Interestingly, female and male affiliation have opposite influences (with husband membership associated with fewer children), but neither of these relationships are significant. The fact that only homogenously LDS couples yield increased fertility is congruent with the economic approaches, "marital stability" and "bargaining effect."

Supporting my fifth hypothesis, model five reflects a relationship between education and LDS fertility similar to that in the United States. To determine the relationship between education and the fertility of LDS women I add the coefficients for the education measure and the interaction term together $(-0.180+0.075)$. The sum is a smaller but still negative coefficient (-0.105 vs. -0.180$)$, indicating that despite the persistent negative association between education and fertility for Mormon wives, the relationship is less negative for these women than for the nation as a whole. The association is even less negative when both spouses are LDS. If just the husband is Mormon, however, the relationship between the wife's education and fertility does not differ significantly from the general population. 


\section{CHILE}

In contrast to Brazil, the fertility rate of Mormon wives in Chile is higher than the national average when controlling for age. These results provide initial support for my first hypothesis which points to the importance of pronatalist doctrine in yielding high fertility among members. When accounting for respondent and spouse characteristics, the coefficient for the LDS wife measure increases, indicating that both doctrine and characteristics influence members' fertility. As in Brazil, education is negatively associated with fertility for both the husband and wife. Because the difference in educational attainment between LDS women and the general population is only slight (see Table 2), however, it appears that the effect of education on Mormon fertility is less pronounced in Chile than in Brazil.

[Table 4 about here]

Although the Chilean data offers perhaps a less interesting analysis of interfaith fertility given that there are few religious categories to compare, the pattern it exhibits is in keeping with my third hypothesis. Although both Jehovah’s Witnesses and other Protestants appear to have fertility rates slightly higher than that of Catholics, Mormons have the highest fertility of any group in this model.

Unlike Brazil, husband-only couples are the only household type whose fertility does not differ from the general population. Both wife-only couples and homogenously LDS couples have higher fertility on average, with the latter exhibiting the highest fertility of the three groups. This is congruent with my fourth hypothesis which predicts lower fertility among LDS interfaith marriages in accordance with marital stability and bargaining effect theories. Finally, results from the fifth model offer support for my fifth hypothesis, but only when both spouses are Mormon. If only one partner is LDS, the relationship between the wife's education and the couple’s fertility is essentially the same as the reference group. 
MEXICO

Similar to Brazil, when controlling only for age female LDS affiliation is associated with lower fertility than the national average; when including characteristics, however, the direction of the relationship changes. In fact, it appears that characteristics account for about $18 \%$ of the difference between Mormon fertility and the national average (see Figure 1). Again, these results provide support for my first and second hypotheses which point to the importance of both theology and characteristics in influencing fertility. In Mexico education also appears to have the largest negative effect on fertility for the respondent, followed by unemployment. While spousal education and unemployment are negatively related to fertility, their effects are much smaller.

[Table 5 about here]

[Figure 1 about here]

Results from the third model also provide support for my third hypothesis, the strict/pronatalist typology. Similar to both Brazil and Mexico, LDS wives have higher fertility than the other denominations included in the analysis. While Seventh-day Adventists and other Protestants have families similar in size to Catholics, Jehovah’s Witnesses have significantly lower fertility. Mainline Protestants and local Protestants have fertility levels that fall in between that of Catholics and Mormons. Offering support for my fourth hypothesis as well, interfaith unions appear to have lower fertility than those homogenously Mormon. Finally, as in Brazil and Chile, the relationship between education and fertility is less negative for "both LDS" couples.

Using expected births, figures 2 through 4 illustrate the negative relationship between education and fertility by household type. In each country and for each type of couple (both LDS, wife LDS, husband LDS or neither LDS) fertility drops as education rises. As the decrease associated with each educational achievement is greater than the difference between household types, these figures indicate that the effect of education on fertility is much greater than that of 
religion. Thus while religion is important (as evidenced by the variance across household type), education exerts a greater influence on fertility. That said, these figures also illustrate that household type does matter for fertility. Most importantly perhaps, homogenously Mormon couples are consistently predicted to have more children at higher levels of education. This is reflective of the less negative relationship between education and fertility for couples in which both spouses are LDS. These graphs also highlight the relatively depressed fertility of husbandonly households as opposed to wife-only ones which exhibit fertility trends closer to "both LDS" couples.

[Figures 2-4 about here]

\section{DISCUSSION}

Although initial results in Brazil and Mexico suggest that the pronatalist pattern of LDS in the United States does not translate to the Latin American context, subsequent models reveal that pronatalism both exists and is pronounced among Mormons in these areas. In the first model the pronatalism of these members is masked by comparatively high educational attainment as well as mixed religion marriages. Once these characteristics and mitigating influences are accounted for, however, LDS fertility is high, especially among the more educated. Characteristics of members appear to be especially important in explaining the LDS/non-LDS fertility difference in Brazil and Mexico (see Figure 1).

Despite Latin American members' comparatively high fertility, the pronatalist pattern of Mormons in these areas is not as consistent as that found in the United States, as illustrated by the results from Brazil and Mexico’s first models. Also interesting is that Chile exhibits a slightly different trend than the other two countries; a strong pronatalist pattern even when not controlling for other factors. These findings suggest not only that the pronatalist pattern of American Mormons does not translate fully, but that the extent to which it transfers varies. I now 
explore some potential explanations for the inconsistency in pronatalist patterns exhibited by different LDS populations.

\section{PRONATALISM}

One of the most important considerations, perhaps, is that the term "pronatalism” encompasses a variety of attitudes, beliefs and behaviors. While pronatalist doctrine is the same in that it encourages fertility, religions can have different beliefs or standards on the issue and be considered equally pronatalist. For instance, even though the LDS and the Catholic churches are both staunch pronatalists, the former has no official stance on birth control usage while the latter opposes contraception. Thus the eternal nature and centrality of family to the LDS faith, as well as the doctrinal and social encouragement to have children, is more reflective of their pronatalism than the Church's position on contraceptives.

Furthermore, it is difficult to determine the extent to which this pattern of pronatalism is a product of LDS doctrine versus culture. In North America there exists an expectation that strong, “active” Mormons will have children and, if possible, large families. These unique ideals about family are not doctrine, however, and it is possible that the cultural conception of what a "good" member is does not translate to Latin America along with the Church’s pronatalist theology. The message members in these areas receive regarding the family would then be more reflective of doctrine (which emphasizes the importance of family) than of American Mormon culture (which emphasizes family size). As a result, perhaps Latin American Mormons are more likely to equate valuing family or being a "good" Mormon with how well they care for their children rather than how many they have. Thus despite my prediction that the Church's pronatalist doctrine fuels the high fertility seen among members in the United States, it is possible that American LDS culture 
has an even stronger or more direct effect on family size. Distinguishing between the influence of Mormon culture and doctrine, however, is beyond the scope of this study.

Also difficult to separate from the influence of pronatalist doctrine is the effect of strictness. While it appears that strictness does matter, given the high fertility of Mormons in comparison to less strict groups, it is unclear to what extent. This is in part because it is a somewhat subjective concept and, as with pronatalism, religions might be equally strict but in different ways. That strictness is associated with higher fertility is important for this analysis, however; further research might examine this relationship more extensively.

\section{CHARACTERISTICS}

As this analysis has demonstrated the importance of member characteristics in influencing fertility, variance in the type of members recruited throughout the world can also in part explain the inconsistency in fertility patterns. As illustrated by figures 2-4, education has a particularly important effect on fertility. While religion may modify education's relationship with fertility (as seen among the more educated members in Latin America), it operates within a certain context and is embedded within the larger socioeconomic system. As a result, religion's influence on fertility is more dependent upon the environment in which it is located and is thus more subject to change. This highlights the importance not only of individual and aggregate levels of education but also selective recruiting. If the average level of member educational attainment varies by place, the fertility of those members likely will also.

It is also possible that those recruited and retained in the Church there differ from other Mormons in ways not captured in this analysis. While this study points to the importance of the demographic characteristics of members, it only begins to increase understanding of who these members are. Couples’ annual income, for instance, either actual or relative was not included in 
this study and is perhaps a significant influence of family size. Other potentially important factors include childhood religion, length of membership in the LDS Church, religious affiliation of parents and the scope of an individual's Mormon social network.

As discussed, the relative newness of an LDS population is another important characteristic given its relationship to mixed religion unions. This analysis indicates that the prevalence of interfaith unions in Latin America where the Church is comparatively less developed does have a depressing effect on LDS fertility. While it appears that women have more influence over the fertility of the couple, as predicted by the economic theories, decisions regarding children are clearly compromised upon by spouses of different faiths. How long the Church has been established in a given area thus has implications for the rate of interfaith unions among members and in part accounts for why pronatalism is more apparent in some areas than in others.

Finally, the characteristics of individual wards might also be important as actual congregations might differ from each other in significant ways. For instance, wards might vary in how well they integrate new members, when they were established, and how long local leaders have been affiliated with the Church; all of which might influence the extent to which members' behavior reflects LDS theology.

\section{THE LDS CHURCH: COUNTRY CONTEXT}

Country context also in part accounts for why Chilean Mormons exhibit different trends than those in Brazil or Mexico. Although Mexico has the largest population of Mormons and Chile the smallest (according to Church records), Chile has the highest per capita membership of these three nations. Percent LDS in Brazil, Chile and Mexico is 0.53, 3.3, and 1.0 respectively; these percentages are substantially smaller when using sources of self-reported religious 
affiliation such as the census. Even though LDS affiliation represents only a small fraction of the population in each of these nations, it is noteworthy that Chile has the highest per capita membership. This might only be meaningful, however, if Mormons are concentrated in specific areas. The extent to which Mormon communities and culture have developed in Latin America is certainly contingent upon the proximity of members to one another. As Chilean members exhibit high fertility despite a low nation-wide average, I suspect that Chile's Mormon population is more concentrated than those in the other two countries. This would likely yield a more developed LDS community and culture that actively promotes profamily ideals. How congregations or communities reinforce pronatalist behavior cannot be determined with demographic data, however, and I can only speculate as to how Mormon culture in Chile differs from other Latin American countries.

Furthermore, the LDS populations in each country have experienced different social, political, economic and theological forces that have influenced Church stability and growth ("CI: Brazil,” 2010; “CI: Chile,” 2010; “CI: Mexico,” 2010). Significant historical factors that hindered expansion include a dictatorship in Chile, wars in Mexico, and pre-1978 restrictions on the priesthood. Given the larger black population in Brazil, the Church’s former policy preventing black members from having the priesthood may have had a greater dampening effect on growth in Brazil than in either Chile or Mexico. This may in part explain the smaller per capita membership in Brazil, as well as members’ comparatively lower fertility.

\section{MACRO-LEVEL EXPLANATIONS}

Macro-level factors, such as each country's level of national development, also influence fertility and might in part account for cross-national differences in LDS fertility. In addition to a longer history of economic development, Chile also has a slightly higher GDP per capita than 
Brazil and Mexico at 15,500, 13,800 and 10,900 (2010) respectively. In fact, as an upper-middle income country and the first in South America to join the OECD, Chile is considered to be one of the continent's wealthiest and most stable economies ("World Factbook,” 2011; “Chile," 2011). It also has a slightly lower poverty rate and a higher Human Development Index than the other two nations, although they are all considered to have "high human development" ("HDI," 2010). Given the negative relationship between development and fertility, as well as Chile’s history of economic development, it is perhaps unsurprising that Chileans have the smallest family size. All three countries are exhibiting similar trends; Chile's fertility has simply been declining longer. It is thus logical that Chilean Mormons appear more pronatalist (as manifest by having larger family size) because the fertility of their reference group is lower than that of Brazil or Mexico.

\section{LIMITATIONS AND CONCLUSIONS}

Because the census uses religious self-identification, the sample represents only a fraction of the population and is substantially smaller than that suggested by LDS Church membership records. In addition, I believe self-identification yields a selection effect in which those that profess to be Mormon are more likely to be dedicated, "active" members of their religion than those that do not. This study then offers insight into the characteristics and fertility not of all those the Church considers to be Mormon, but of a segment of that population.

Despite its limitations this study has shed light on important changes in the religious environment of Latin America today. It has also lent insight into the demographic trends of a strict, pronatalist American-born Church in a deCatholicizing context. More specifically, this analysis has furthered understanding of how different LDS populations compare and the implications those differences have for growth. Understanding the fertility of Mormons in diverse areas elucidates whether the growth trends of LDS in the United States are the exception 
or the rule and what these patterns mean for the future of the Church. This analysis suggests that the high fertility of American members may be an anomaly as of now, but as the Church continues to develop and attract similar types of adherents the LDS pattern of pronatalism will become more pronounced throughout the world.

This analysis also has broader implications for religions expanding into developing nations. Even when doctrine is standardized across country there are various forces that influence the reception, interpretation and enactment of those beliefs. The extent to which member behavior is reflective of a denomination's theology is somewhat contingent upon selective recruiting, and who is attracted to and retained by a religion varies by context. As in the case of the Mormons, where the membership and proselytizing efforts are concentrated in part determines the type of person that is exposed and converts to the faith. Furthermore, just as member characteristics vary, the culture of the recently introduced religion may differ from areas in which it is more established. Because practices and behaviors are shaped by many different influences, expanding religions should thus expect variance in family structure and growth patterns exhibited by members in different contexts. 


\section{REFERENCES}

2011 Deseret News Church Almanac. 2011. Salt Lake City, UT: Deseret News.

Adsera, Alicia. 2006a. “Marital Fertility and Religion in Spain, 1985 and 1999.” Population Studies 60(2): 205-221.

------. 2006b. "Religion and Changes in Family-Size Norms in Developed Countries.” Review of Religious Research 47(3): 271-286.

“Appendix 3: Classification of Protestant Denominations.” 2008. Pew Forum on Religion \& Public Life/U.S. Religious Landscape Survey. Retrieved March 3, 2011 (http://religions.pewforum.org/pdf/report2religious-landscape-study-appendix3.pdf).

Bahr, Howard M. and Renata Tonks Forste. 1998. “Toward a Social Science of Contemporary Mormondom.” Pp 133 in Latter-day Saint Social Life: Social Research on the LDS Church and its Members, edited by James T. Duke. Salt Lake City, UT: Bookcraft, Inc.

Caldwell, J. 1980. "Mass Education as a Determinant of the Timing of Fertility Decline." Population and Development Review 6: 225-55.

Chaves, Mark. 1994. “Secularization as Declining Religious Authority.” Social Forces 72(3): 749-774.

“Chile.” 2011. The World Bank. Retrieved May 17, 2011 (http://data.worldbank.org/country/chile).

“Country Information: Brazil.” 25 Jan 2010. Church News: The Church of Jesus Christ of Latter-day Saints. Retrieved May 15, 2011 (http://www.ldschurchnews.com/articles/58508/Country-information-Brazil.html). 
“Country Information: Chile.” 28 Jan 2010. Church News: The Church of Jesus Christ of Latter-day Saints. Retrieved May 15, 2011

(http://www.ldschurchnews.com/articles/58523/Country-information-Chile.html).

“Country Information: Mexico.” 29 Jan 2010. Church News: The Church of Jesus Christ of Latter-day Saints. Retrieved May 15, 2011

(http://www.ldschurchnews.com/articles/58617/Country-information-Mexico.html).

“Country Studies.” 2010. The Library of Congress. Retrieved November 4, 2010

(http://memory.loc.gov/frd/cs/cshome.html).

Courgeau, D. 1989. “Family Formation and Urbanization.” Population: An English Selection 44(1): 123-146.

"The Future of Fertility in Intermediate-Fertility Countries." n.d. Population Division, Department of Economic and Social Affairs, United Nations Secretariat. Retrieved November 1, 2010

(http://www.un.org/esa/population/publications/completingfertility/RevisedPEPSPOPD IVpaper.PDF).

“Fertility Rate, Total (Births per Woman)." 2010. The World Bank, for a World Free of Poverty. Retrieved November 13, 2010

(http://data.worldbank.org/indicator/SP.DYN.TFRT.IN).

"Frequently Asked Questions (FAQ).” n.d. IPUMS International. Retrieved June 15, 2011 (https://international.ipums.org/international/).

“GDP per Capita (Current US\$).” 2010. The World Bank: For a World Free of Poverty. Retrieved November 13, 2010 (http://data.worldbank.org/indicator/NY.GDP.PCAP.CD?display=graph). 
Goldscheider, Calvin. 1971. Population, Modernization, and Social Structure. Boston: Little, Brown and Company.

------. 1999. “Religious Values, Dependencies, and Fertility: Evidence and Implications from Israel,” in R. Leete (ed.), Dynamics of Values in Fertility Change. Oxford: Oxford University Press, pp. 310-330.

Grover, Mark L. 2005. "The Maturing of the Oak: The Dynamics of LDS Growth.” Dialogue: A Journal of Mormon Thought. Retrieved October 5, 2011 (https://dialoguejournal.com/wpcontent/uploads/sbi/articles/Dialogue_V38N02_91.pdf).

Heaton, Tim B. 1994. “The Demography of Utah Mormons.” Pp 249-254 in Multiply and Replenish: Mormon Essays on Sex and Family, edited by Brent Corcoran. Salt Lake City, UT: Signature Books.

-----. 1998a. "Vital Statistics.” Pp 105-112 in Latter-day Saint Social Life: Social Research on the LDS Church and its Members, edited by James T. Duke. Salt Lake City, UT: Bookcraft, Inc.

------. 1998b. “Religious Influences on Mormon Fertility: Cross-National Comparisons.” Pp 425-437 in Latter-day Saint Social Life: Social Research on the LDS Church and its Members, edited by James T. Duke. Salt Lake City, UT: Bookcraft, Inc. Heaton, Tim B.; Stephen J. Bahr and Cardell K. Jacobson. 2004. A Statistical Profile of Mormons: Health, Wealth and Social Life. Lewiston, NY: The Edwin Mellen Press. Heaton, Tim B.; J. Lynn England and David Knowlton. 2010. "Religious Diversity in Mexico: Socioeconomic Attainment and Family Structure.” Unpublished manuscript. 
Heineck, Guido. 2005. “The Relationship between Religion and Fertility: Evidence for Austria.” L'Association D'Econometrie Appliquee. Retrieved September 21, 2011 (http://www.aea-eu.com/2005Pau/DOC/resu_abstract/Heineck.pdf).

Hollos, Marida and Ulla Larsen. 2008. "Motherhood in Sub-Saharan Africa: The Social Consequences of Infertility in an Urban Population in Northern Tanzania.” Culture, Health and Sexuality 10(2): 159-173.

“Human Development Index (HDI) 2010 Rankings.” 2010. Human Development Reports. Retrieved May 17, 2011 (http://hdr.undp.org/en/statistics/).

Iannaccone, Laurence R. 1994. "Why Strict Churches are Strong.” American Journal of Sociology 99(5): 1180-1211.

Kelley, Dean M. (1972) 1986. Why Conservative Churches are Growing: A Study in the Sociology of Religion. Macon, GA: Mercer University Press.

Knowlton, David Clark. 2005. "How Many Members Are There Really? Two Censuses and the Meaning of LDS Membership in Chile and Mexico.” Dialogue: A Journal of Mormon Thought. Retrieved October 5, 2011 (http://www.dialoguejournal.com/wpcontent/uploads/sbi/articles/Dialogue_V38N02_65.pdf).

Kravdal, Oystein. 2000. “A Search for Aggregate-Level Effects of Education on Fertility, Using Data from Zimbabwe.” Demographic Research 3(3).

Kravdal, Oystein. 2001. “Main and Interaction Effects of Women's Education and Status on Fertility: The Case of Tanzania.” European Journal of Population 17:107-136.

Kravdal, Oystein, and Ronald Rindfuss. 2008. "Changing Relationships between Education and Fertility: A Study of Women and Men Born 1940-1964.” American Sociological Review 73(5): 854-873. 
Kulu, H. and J. Boyle. 2009. "High Fertility in City Suburbs: Compositional or Contextual Effects?” European Journal of Population 25:157-174.

Lawson, Ronald. n.d. "Reassessing the Size of Mormons, Adventists and Witnesses: Exploring the Dynamics of their Global Growth and Testing the Reliability of their Membership Data.” Retrieved October 10, 2011 (http://www.sdahistorians.org/uploads/Lawson_2_Reassessing_Size.pdf).

Lehrer, Evelyn L. 1996. "The Role of the Husband's Religious Affiliation in the Economic and Demographic Behavior of Families.” Journal for the Scientific Study of Religion 35(2): 145-155.

------. 2004. "Religion as a Determinant of Economic and Demographic Behavior in the United States.” Population and Development Review 30(4): 707-726.

McQuillan, Kevin. 2004. "When Does Religion Influence Fertility? Population and Development Review 30(1): 25-56.

Mosher, William D.; Linda B. Williams, and David P. Johnson. 1992. "Religion and Fertility in the United States: New Patterns.” Demography 29(2): 199-214.

Pitcher, Brian L.; Evan T. Peterson and Phillip R. Kunt. 1974. "Residency Differentials in Mormon Fertility.” Population Studies 28(1): 143-151.

Stark, Rodney. 1994. "Modernization and Mormon Growth: The Secularization Thesis Revisited.” In Contemporary Mormonism: Social Science Perspectives, edited by Marie Cornwall, Tim B. Heaton and Lawrence A. Young. Urbana, IL: University of Illinois Press. 
Stark, Rodney. 1998. “The Basis of Mormon Success: A Theoretical Application.” In Latterday Saint Social Life: Social Research on the LDS Church and its Members, edited by James T. Duke. Salt Lake City, UT: Bookcraft, Inc.

Szreter, S. 1996. Fertility, Class and Gender in Britain 1860-1940. Cambridge: Cambridge University Press.

Szreter, S. and Garrett, E. 2000. "Reproduction, Compositional Demography, and Economic Growth: Family Planning in England Long Before the Fertility Decline.” Population and Development Review 26(1): 45-80.

Thomas, D. 1999. “Fertility, Education and Resources in South Africa.” In: C. H. Bledsoe, J. B. Casterline, J. A. Johnson-Kuhn and J. G. Haaga, editors. Critical Perspectives on Schooling and Fertility in the Developing World. Washington: National Academy Press: pp.138-180.

“The World Factbook.” 2011. Central Intelligence Agency. Retrieved February 27, 2011 (https://www.cia.gov/library/publications/the-world-factbook/).

Zhang, Li. 2008. "Religious Affiliation, Religiosity and Male and Female Fertility.” Demographic Research 18(8): 233-261. 
Table 1 LDS Household Type by Country (\%)

\begin{tabular}{lccc}
\hline & Brazil & Chile & Mexico \\
\hline Just Wife & 546 & 1,209 & 1,403 \\
& $(0.03)$ & $(0.40)$ & $(0.05)$ \\
Just Husband & 285 & 557 & 623 \\
& $(0.01)$ & $(0.19)$ & $(0.02)$ \\
\multirow{2}{*}{ Both } & 1,349 & 1,612 & 3,242 \\
& $(0.07)$ & $(0.54)$ & $(0.15)$ \\
\hline
\end{tabular}

Source: Brazil census (2000), Chile census (2002),

Mexico census (2000), retrieved from IPUMS International 
Table 2 Descriptive Statistics, Comparing LDS Wives to the National Averages of Brazil, Chile and Mexico Source: Brazil census (2000), Chile census (2002), Mexico census (2000), retrieved from IPUMS International

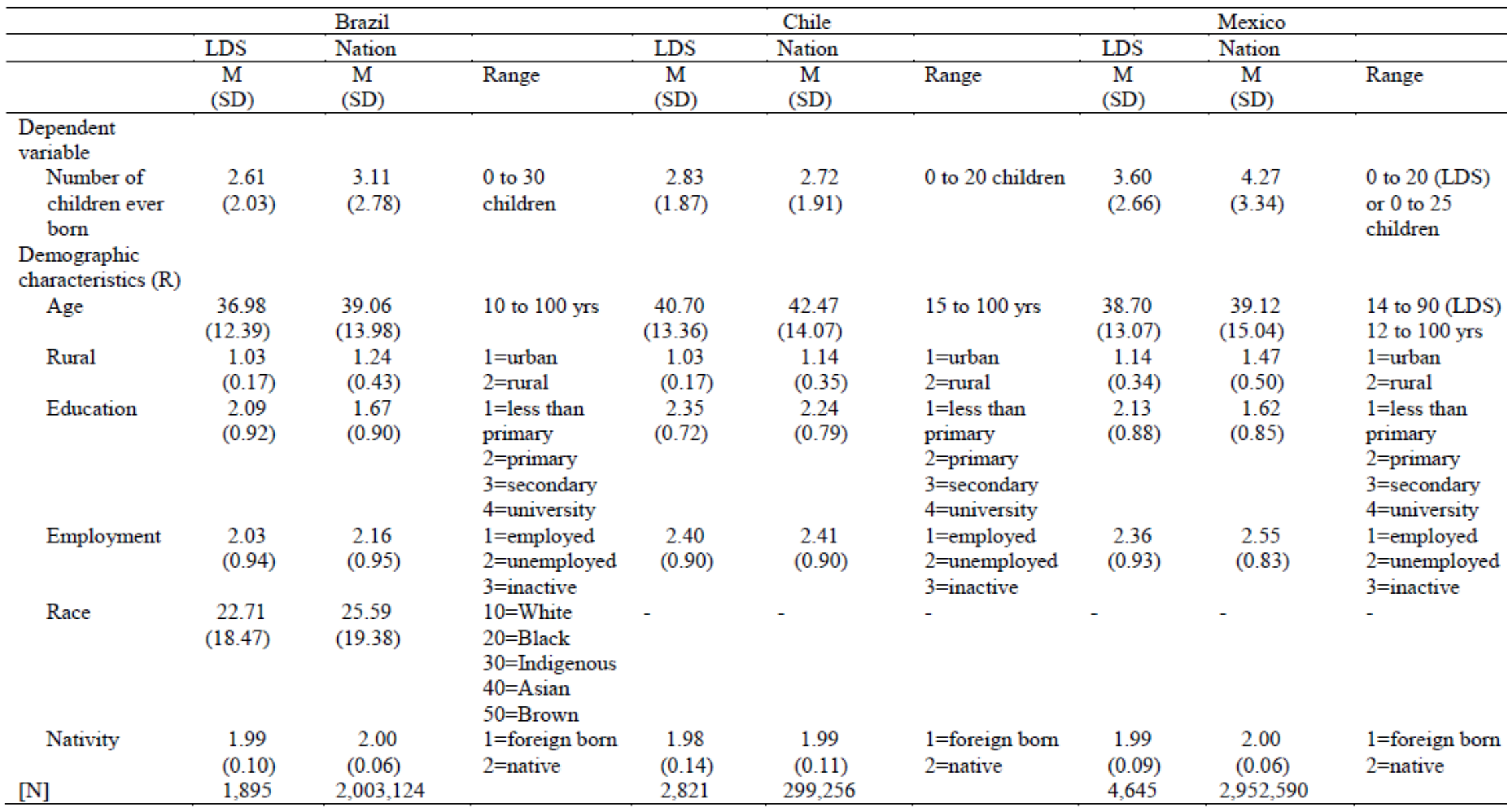




\begin{tabular}{|c|c|c|c|c|c|}
\hline Characteristics & Model 1 & Model 2 & Model 3 & Model 4 & Model 5 \\
\hline \multicolumn{6}{|l|}{$L D S$} \\
\hline Wife LDS & $-0.093 * * *$ & $0.084^{* * *}$ & $0.090^{* * * *}$ & & \\
\hline Just Wife LDS & & & & 0.019 & -0.113 \\
\hline Just Husband LDS & & & & -0.052 & -0.030 \\
\hline Both LDS & & & & $0.112^{* * * *}$ & -0.090 \\
\hline Age & $0.030 * * *$ & $0.029 * * *$ & $0.029 * * *$ & $0.029^{* * * *}$ & $0.029 * * *$ \\
\hline \multicolumn{6}{|l|}{ Demographic } \\
\hline \multicolumn{6}{|l|}{ Characteristics (R) } \\
\hline Rural & & $0.185^{* * *}$ & $0.189 * * *$ & $0.185^{* * * *}$ & $0.185^{* * * *}$ \\
\hline Education & & 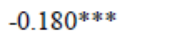 & $-0.178 * * *$ & $-0.180^{* * * *}$ & $-0.180^{* * * *}$ \\
\hline Unemployed & & 0.002 & 0.000 & 0.002 & 0.002 \\
\hline Inactive (in labor force) & & $0.013^{* * *}$ & $0.011^{* * * *}$ & $0.013^{* * *} *$ & $0.013^{* * *}$ \\
\hline \multicolumn{6}{|l|}{ Race } \\
\hline Black & & $0.109^{* * *}$ & $0.107^{* * *}$ & $0.109^{* * * *}$ & $0.109^{* * * *}$ \\
\hline Indigenous & & $0.175^{* * *}$ & $0.174 * * *$ & $0.175^{* * * *}$ & $0.175^{* * * * *}$ \\
\hline Brown & & $0.145^{* * *}$ & $0.143^{* * * *}$ & $0.145^{* * * *}$ & $0.145^{* * * *}$ \\
\hline Asian & & $-0.051^{* * * * *}$ & $-0.050^{* * * *}$ & $-0.051^{* * * *}$ & $-0.051^{* * * *}$ \\
\hline Missing & & $0.085^{* * * *}$ & $0.083^{* * * *}$ & $0.085^{* * * *}$ & $0.085^{* * * *}$ \\
\hline Native & & $0.167^{* * *}$ & $0.164 * * *$ & $0.167 * * *$ & $0.167^{* * * *}$ \\
\hline \multicolumn{6}{|l|}{ Demographic } \\
\hline \multicolumn{6}{|l|}{ Characteristics (S) } \\
\hline Education & & $-0.094^{* * * *}$ & $-0.092^{* * *}$ & $-0.094^{* * * *}$ & $-0.094 * * *$ \\
\hline Unemployed & & 0.004 & 0.002 & 0.004 & 0.004 \\
\hline Inactive (in labor force) & & $-0.090^{* * * *}$ & $-0.090^{* * *}$ & $-0.090^{* * * *}$ & $-0.090^{* * *}$ \\
\hline \multicolumn{6}{|l|}{ Race } \\
\hline Black & & $0.139 * * *$ & $0.136^{* * * *}$ & $0.139^{*} * * *$ & $0.139^{* * * * *}$ \\
\hline Indigenous & & $0.141^{* * *}$ & $0.137^{* * * *}$ & $0.141^{* * * * *}$ & $0.141^{* * * * *}$ \\
\hline Brown & & $0.136^{* * *}$ & $0.134^{* * * *}$ & $0.136^{* * * *}$ & $0.136^{* * * *}$ \\
\hline Asian & & $0.047^{* * *}$ & $0.047^{* * * *}$ & $0.047 * * *$ & $0.047 * * *$ \\
\hline Missing & & $0.087 * * *$ & $0.086^{* * * *}$ & $0.087 * * *$ & $0.087 * * *$ \\
\hline Native & & $0.235^{* * *} *$ & $0.232 * * *$ & $0.235^{* * * *}$ & $0.235^{* * * *}$ \\
\hline \multicolumn{6}{|l|}{ Religious Affiliation } \\
\hline Jehovah's Witness & & & $-0.048^{\text {***** }}$ & & \\
\hline Seventh day Adventist & & & $0.027^{* * * *}$ & & \\
\hline Mainline Protestant & & & $-0.078 * * *$ & & \\
\hline Other Protestant & & & 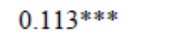 & & \\
\hline \multirow{2}{*}{\multicolumn{6}{|c|}{ Interactions }} \\
\hline & & & & & \\
\hline Just Wife LDS/edu & & & & & $0.075^{*}$ \\
\hline Just Husband LDS/edu & & & & & -0.013 \\
\hline Both LDS/edu & & & & & $0.103 * * * *$ \\
\hline$[\mathrm{N}]$ & $2,003,124$ & $2,003,124$ & $2,003,124$ & $2,003,124$ & $2,003,124$ \\
\hline LR Chi Squared & $635,032.00^{* * * *}$ & $990,726.33^{* * *}$ & $995,646.03^{* * * *}$ & $990,734.4^{* * * * *}$ & $990,762.17 * * * *$ \\
\hline Pseudo $\mathrm{R}^{2}$ & 0.072 & 0.113 & 0.113 & 0.113 & 0.113 \\
\hline
\end{tabular}

Source: Brazil census (2000), retrieved from IPUMS International

Note: ${ }^{*} \mathrm{p}<0.05,{ }^{* *} \mathrm{p}<0.01,{ }^{* * *} \mathrm{p}<0.001$ 
Table 4 Negative Binomial Regression Coefficients of Children Ever Born, Chile

\begin{tabular}{|c|c|c|c|c|c|}
\hline Characteristics & Model 1 & Model 2 & Model 3 & Model 4 & Model 5 \\
\hline \multicolumn{6}{|l|}{$L D S$} \\
\hline Wife LDS & $0.083^{* * * *}$ & 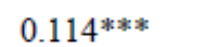 & $0.134^{* * * *}$ & & \\
\hline Just Wife LDS & & & & $0.082^{\text {***k }}$ & 0.038 \\
\hline Just Husband LDS & & & & -0.025 & -0.121 \\
\hline Both LDS & & & & $0.136^{\text {*k:k }}$ & 0.005 \\
\hline Age & $0.022 * * *$ & 0.019 **** & $0.019^{* * * *}$ & 0.019 **** & $0.019^{\text {*k*** }}$ \\
\hline \multicolumn{6}{|l|}{ Socioeconomic } \\
\hline \multicolumn{6}{|l|}{ Characteristics ( $R$ ) } \\
\hline Education & & $-0.134^{\text {*冰水 }}$ & $-0.128 * * *$ & $-0.134^{* * *}$ & $-0.134^{\text {**** }}$ \\
\hline Unemployed & & -0.003 & -0.004 & -0.003 & -0.003 \\
\hline Inactive in labor force & & 0.079 米米 & $0.076^{* * * *}$ & $0.079^{*}: * * k$ & 0.079 ***** \\
\hline Native & & $0.040^{* * * *}$ & $0.039^{* * * *}$ & $0.039 * * * *$ & $0.039^{*} * * * *$ \\
\hline \multicolumn{6}{|l|}{ Socioeconomic } \\
\hline \multicolumn{6}{|l|}{ Characteristics (S) } \\
\hline Education & & $-0.001^{* * * * *}$ & $-0.001^{* * * * *}$ & $-0.001^{* * * * *}$ & $-0.001^{* * * *}$ \\
\hline Education missing & & $-0.026^{* * * *} *$ & $-0.026^{* * * *}$ & $-0.025^{* * * *}$ & $-0.025^{* * * *}$ \\
\hline Inactive in labor force & & $-0.026^{* * * * *}$ & $-0.026^{* * * *}$ & $-0.026^{* * * *}$ & $-0.026^{* * * *}$ \\
\hline Native & & $0.111^{* * * *}$ & $0.110^{* * * *}$ & $0.112^{* * * * *}$ & $0.111^{\text {*k:k }}$ \\
\hline \multicolumn{6}{|l|}{ Religious Affiliation } \\
\hline Jehovah's witness & & & $0.038^{* * \cdots *}$ & & \\
\hline Other protestant & & & $0.103^{* * \cdots}$ & & \\
\hline \multicolumn{6}{|l|}{ Interaction terms } \\
\hline Just Wife LDS/edu & & & & & 0.020 \\
\hline Just Husband LDS/edu & & & & & 0.044 \\
\hline Both LDS/edu & & & & & $0.059 * *$ \\
\hline$[\mathrm{N}]$ & 299,256 & 299,256 & 299,256 & 299,256 & 299,256 \\
\hline LR Chi Squared & $78,443.96$ **** & $99,395.39^{* * *}$ & 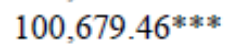 & $99,402.08$ * * * * * & $99,413.02$ **** \\
\hline Pseudo $\mathrm{R}^{2}$ & 0.068 & 0.086 & 0.087 & 0.086 & 0.086 \\
\hline
\end{tabular}

Source: Chile census (2002), retrieved from IPUMS International

Note: ${ }^{*} \mathrm{p}<0.05,{ }^{*}{ }^{*} \mathrm{p}<0.01,{ }^{*} k_{*} \mathrm{p}<0.001$ 
Table 5 Negative Binomial Regression Coefficients of Children Ever Born, Mexico

\begin{tabular}{|c|c|c|c|c|c|}
\hline Characteristics & Model 1 & Model 2 & Model 3 & Model 4 & Model 5 \\
\hline \multicolumn{6}{|l|}{$L D S$} \\
\hline Wife LDS & $-0.110^{* * * * *}$ & $0.070^{* * * *}$ & $0.071^{* * * *}$ & & \\
\hline Just Wife LDS & & & & 0.002 & -0.079 \\
\hline Just Husband LDS & & & & 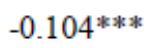 & $-0.169^{*}$ \\
\hline Both LDS & & & & $0.098^{* * * *}$ & -0.060 \\
\hline Age & $0.032^{* * * *}$ & $0.026^{* * * *}$ & $0.026^{* * * *}$ & $0.026^{* * * *}$ & $0.026^{* * *}$ \\
\hline \multicolumn{6}{|l|}{ Socioeconomic } \\
\hline \multicolumn{6}{|l|}{ Characteristics $(R)$} \\
\hline Rural & & $0.104^{* * * *}$ & $0.104^{* * * *}$ & $0.104^{* * * * *}$ & $0.104^{* * * *}$ \\
\hline Education & & $-0.204 * * *$ & $-0.204^{* * * *}$ & $-0.204^{* * * *}$ & $-0.205^{* * * *}$ \\
\hline Unemployed & & $-0.205^{* * * *}$ & $-0.205^{* * * *}$ & $-0.205^{* * * *}$ & $-0.205^{* * * *}$ \\
\hline Inactive in labor force & & $0.009 * * *$ & $0.009 * * * *$ & $0.009 * * *$ & $0.009 * * *$ \\
\hline Native & & 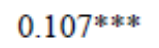 & 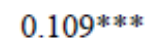 & 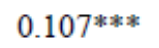 & $0.107^{* * * * *}$ \\
\hline \multicolumn{6}{|l|}{ Socioeconomic } \\
\hline \multicolumn{6}{|l|}{ Characteristics (S) } \\
\hline Education & & 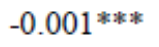 & $-0.001^{* * *} \cdot{ }^{*}$ & $-0.001^{*} k_{*} \cdot k_{k}$ & 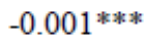 \\
\hline Education missing & & $0.097^{\text {*k*k }}$ & $0.097^{* * * *} *$ & 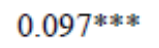 & $0.097^{* * *} *$ \\
\hline Unemployed & & $-0.011 *$ & $-0.011^{*}$ & $-0.011^{*}$ & $-0.011^{*}$ \\
\hline Inactive in labor force & & $-0.070 * * *$ & $-0.069 * * *$ & $-0.070 * * *$ & 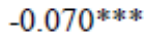 \\
\hline Employment missing & & $-0.196^{* * * *}$ & $-0.196^{* * * *}$ & $-0.196^{* * * *}$ & $-0.196^{* * * *}$ \\
\hline Native & & $0.138^{* * * * *}$ & $0.139^{*} k^{*} k^{*}$ & $0.138^{* * * *}$ & $0.138 * * *$ \\
\hline \multicolumn{6}{|l|}{ Religious Affiliation } \\
\hline Jehovah's Witness & & & $-0.023^{* * *}$ & & \\
\hline Seventh day Adventist & & & 0.001 & & \\
\hline Mainline Protestant & & & $0.023^{* * * *}$ & & \\
\hline Other Protestant & & & -0.006 & & \\
\hline Local Protestant & & & $0.030^{* * * * *}$ & & \\
\hline \multicolumn{6}{|l|}{ Interaction Terms } \\
\hline Just Wife LDS/edu & & & & & 0.039 \\
\hline Just Husband LDS/edu & & & & & 0.032 \\
\hline Both LDS/edu & & & & & $0.079 * * *$ \\
\hline$[\mathrm{N}]$ & $1,998,830$ & $1,998,830$ & $1,998,830$ & $1,998,830$ & $1,998,830$ \\
\hline
\end{tabular}

Source: Mexico (2000), retrieved from IPUMS International

Note: ${ }^{*} \mathrm{p}<0.05,{ }^{*}{ }^{*} \mathrm{p}<0.01,{ }^{* * *} \mathrm{p}<0.001$

Note: No LR Chi Squared or Pseudo $\mathrm{R}^{2}$ reported after multiple imputation 
Figure 1

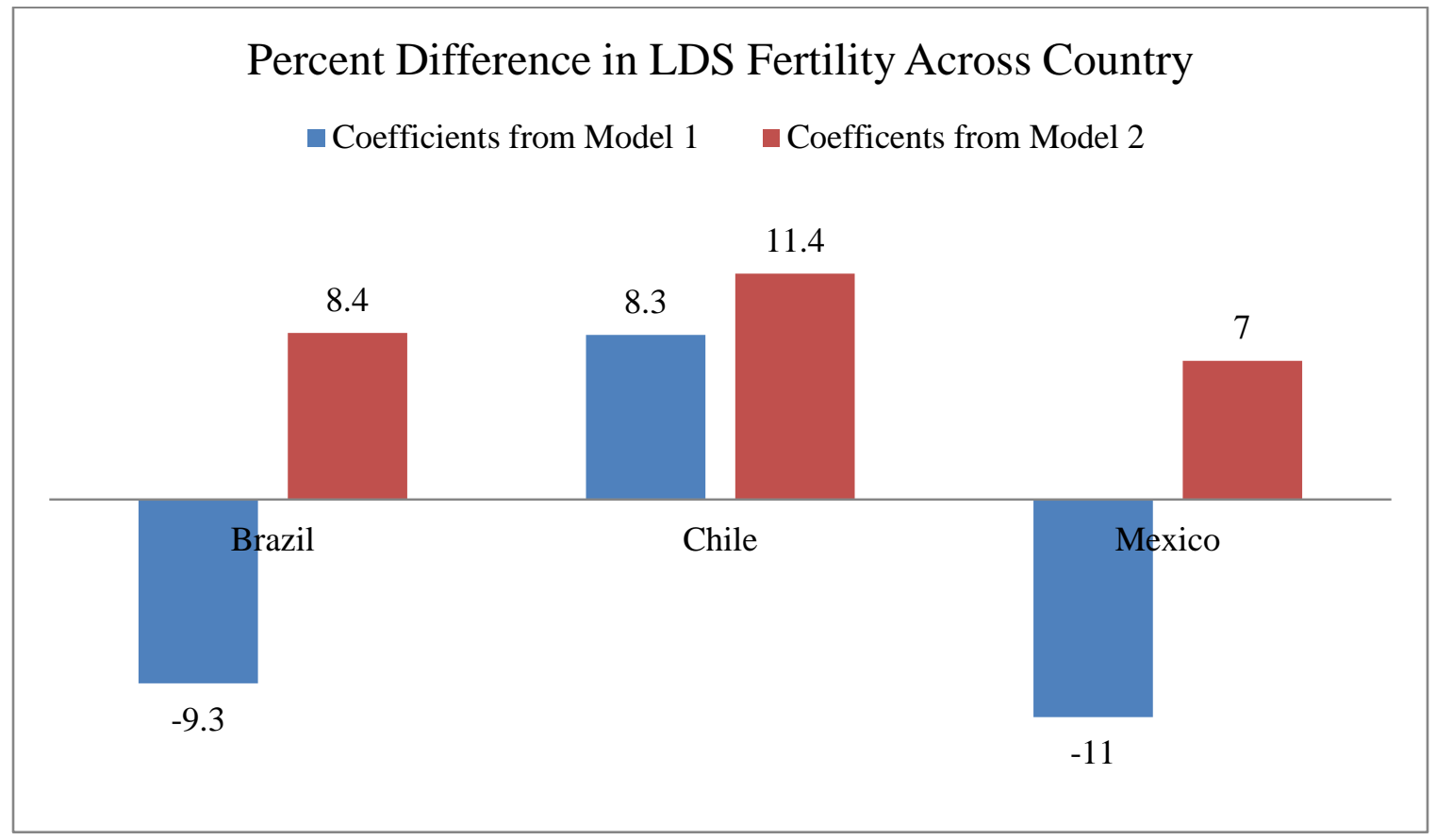


Figure 2

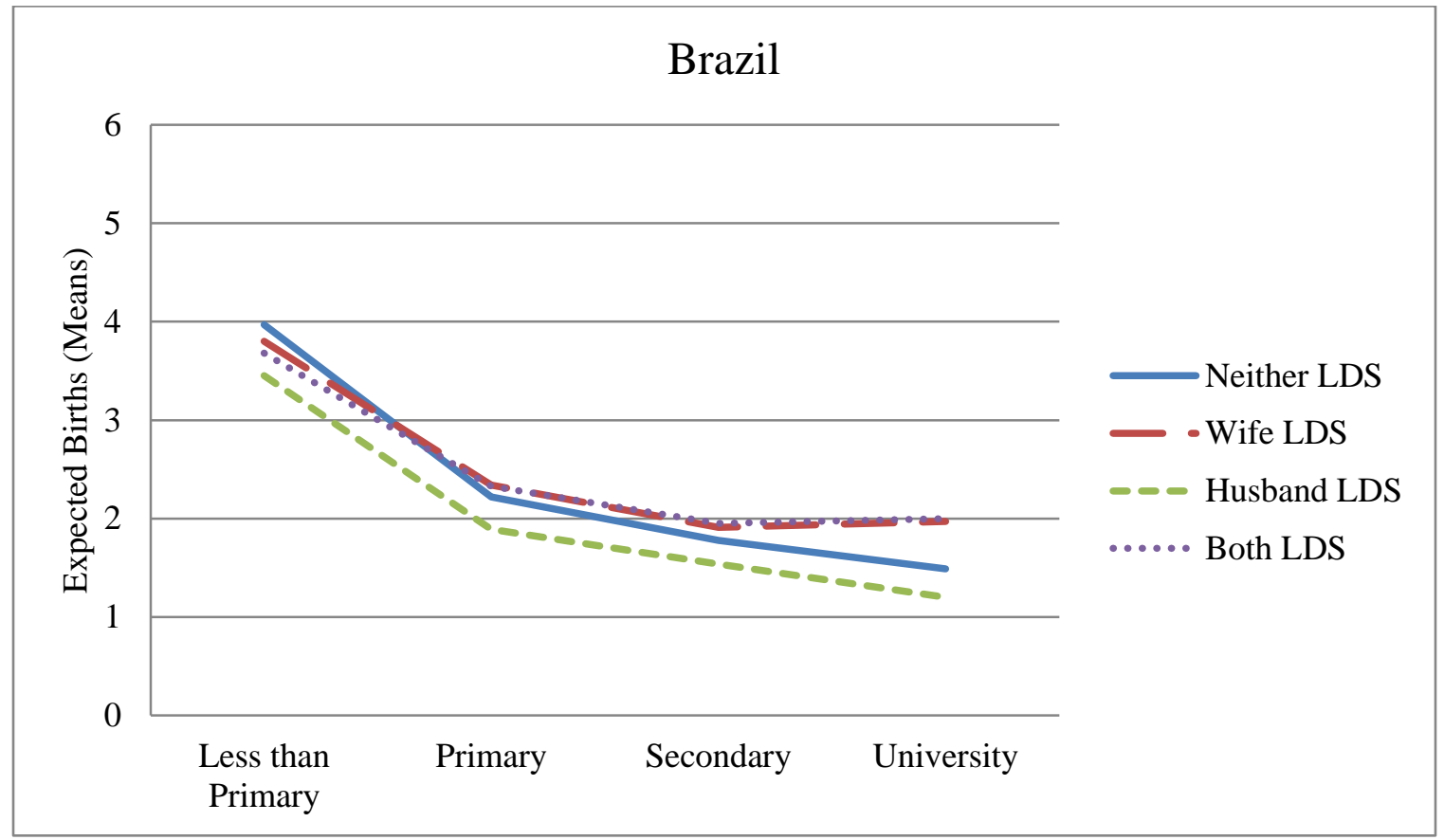


Figure 3

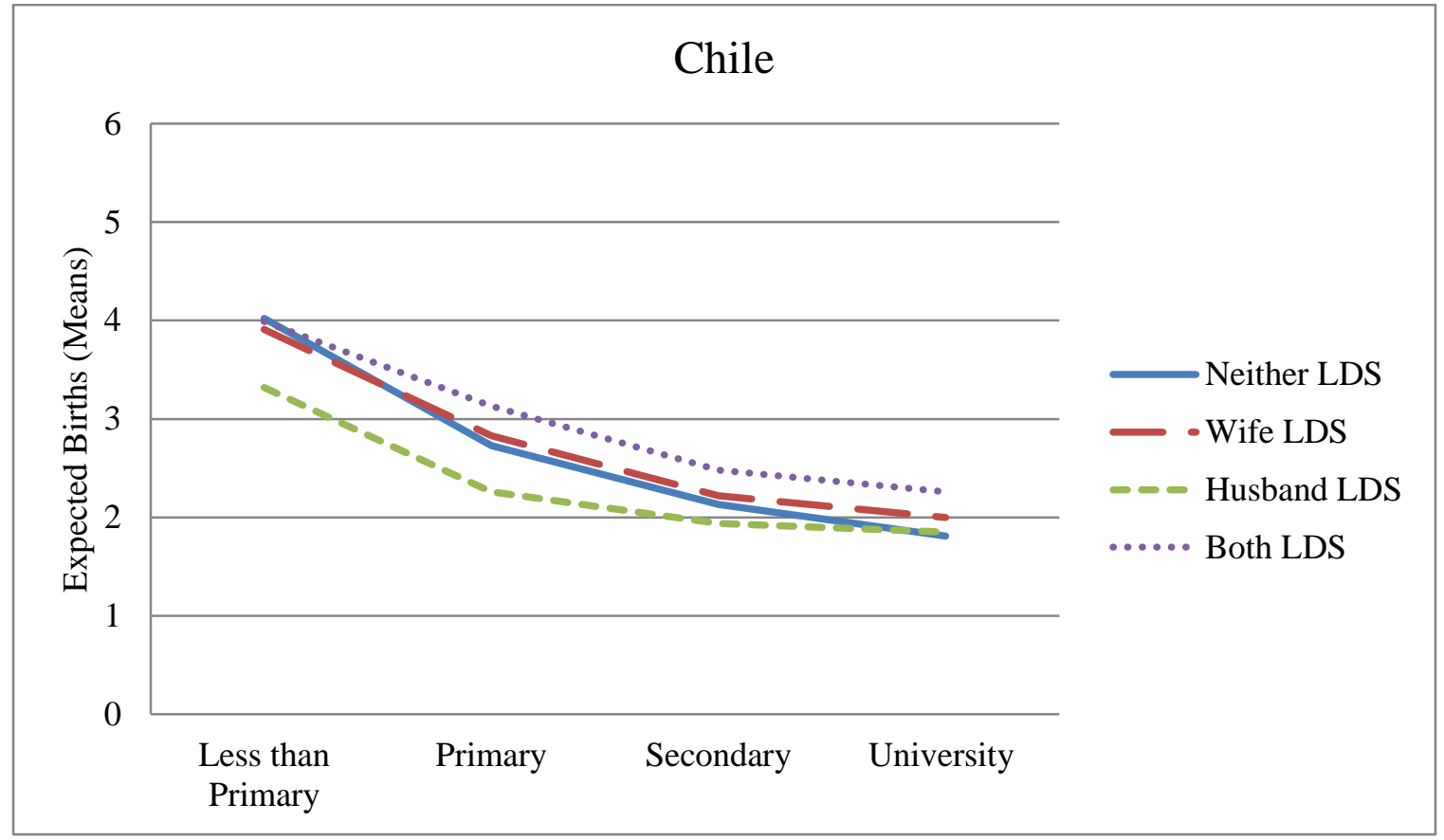


Figure 4

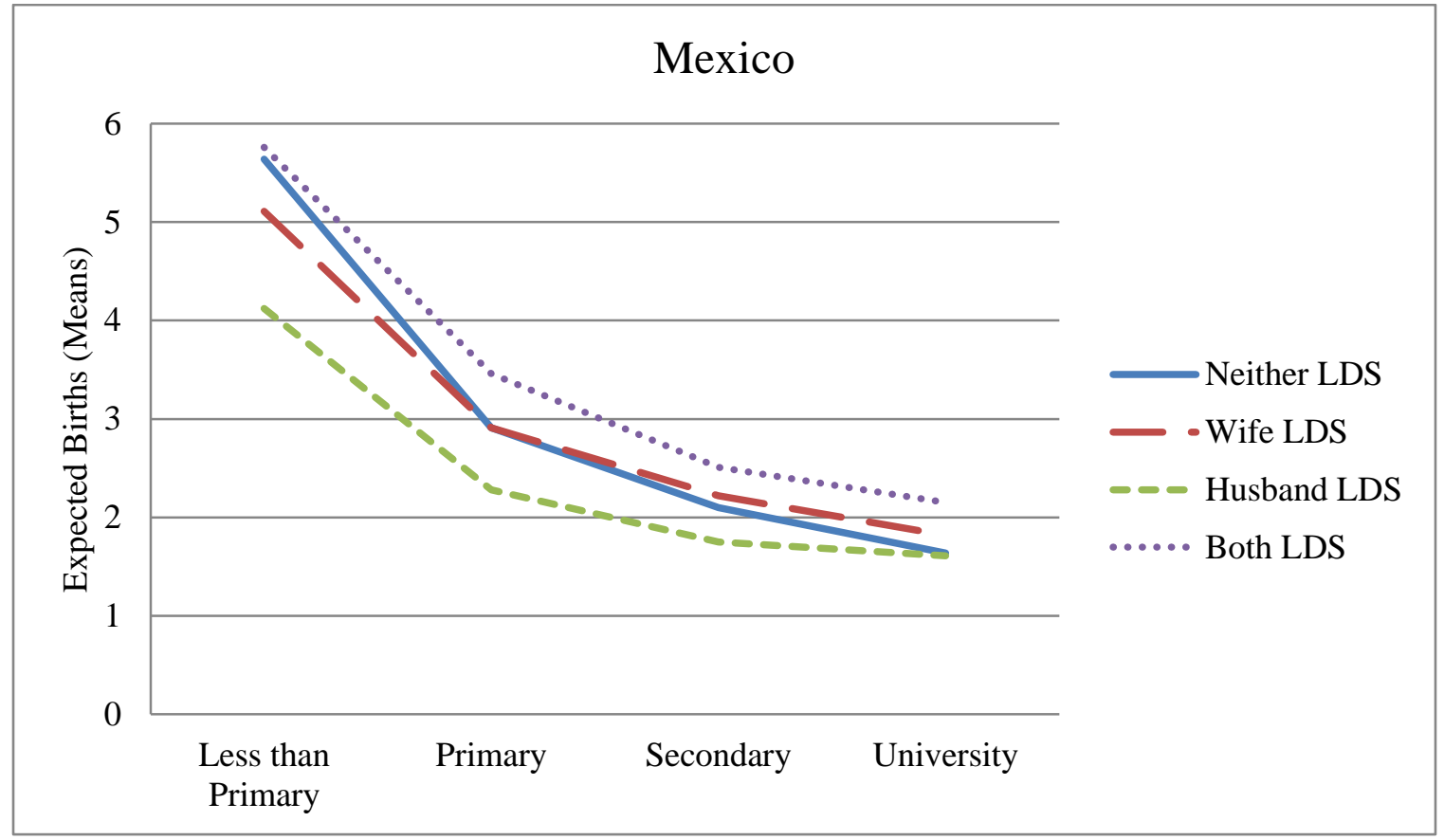

